\title{
Establishment of stem cell bank in China
}

\author{
Guo-Tong $\mathrm{Xu}^{1,2}$ \\ ${ }^{1}$ Institute of Health Sciences, Shanghai Institutes for Biological Sciences, Chinese Academy of Sciences, and Shanghai Jiaotong \\ University School of Medicine; ${ }^{2}$ Key Laboratory of Stem Cell Biology of Chinese Academy of Sciences, Shanghai, China
}

As one of the major projects under the "Developmental and Reproductive Research Initiation" organized and sponsored by the Ministry of Science and Technology of China, a national Stem Cell Bank (SCB) network will be established in the coming 4-5 years. Several institutions in Shanghai will collaborate with the teams in Beijing and Guangzhou as well as other cities to make the China SCB a successful network. The key missions of the SCB network include: (1) building a public resources for embryonic stem cells (ESC) supply, mainly hESC, (2) building a platform for developing key stem cell technology and sharing the technology with other scientists in stem cell research, and (3) building a central database and website for information management and sharing to facilitate information and material exchange and research collaboration, within China or internationally. The key components of the plan are the establishment of four stem cell banks in Beijing/Tianjin, Shanghai and Guangzhou to serve North, South and East China, where most of the key Chinese stem cell research scientists live and work at this moment. Later on the service and technical support will cover more area in China. International standards will be employed in the establishment and development of the SCB, including the facilities, the functions, the procedure, quality control and other important issues beyond the science and technology like legal, ethics, service, funding mechanism and so on. The goals for the phase I development of SCB will also include the establishment of some high quality human embryonic stem cell lines, and establishment of training and technique support platform. Efforts for later phase I will focus on promoting the clinical research with stem cell approaches, so that the establishment of clinical grade hESCs will be one of the key focuses. For information sharing, a central database will be developed and the website is currently under construction. International collaboration will be one of the considerations with high priority. Through such collaborations, we can learn from each other share the resources and advantages with other countries.

Keywords: stem cell bank, human embryonic stem cell

Cell Research (2008) 18:s175. doi: 10.1038/cr.2008.265; published online 4 August 2008

Correspondence: Guo-Tong Xu

E-mail: gtxu@sibs.ac.cn

Guo-Tong $\mathrm{Xu}, \mathrm{MD} / \mathrm{PhD}$, graduated from Harbin Medical University with a bachelor degree in 1982. He later received a MD degree from Peking Union Medical College, Chinese Academy of Medical Sciences, and $\mathrm{PhD}$ in pharmacology from University of North Texas Health Science Center (UNTHSC), USA. After trained in Alcon Lab., Inc., R\&D, and NEI/NIH, He was appointed as an assistant professor at UNTHSC, before he returned to China. Currently, he is a Principal Investigator,
Professor and the Acting Director of the Institute of Health Sciences, Shanghai Institutes for Biological Sciences, Chinese Academy of Sciences (CAS), and Shanghai Jiaotong University School of Medicine. Starting 2006, his lab was accepted as a member of the Key Laboratory of Stem Cell Biology of CAS. Dr Xu's research focuses on aging and metabolic eye diseases, including the development of new drugs and new therapies for diabetic retinopathy and age-related macular degeneration. He is now in charge of the establishment and development of a net work of stem cell banks in China. Please visit his lab website for more details. http://www. ihs.ac.cn/en/ep2-5-2-LCVS-xugt.asp 